\section{Older people, information, and social networks in rural Cumbria: doctoral research in progress}

\author{
Dr Linda Banwell, \\ Susan Elizabeth Capel
}

\begin{abstract}
Authors
Dr Linda Banwell is Reader in Information and Communication Management and is currently leading the I-Society Research and Consultancy Group at Northumbria University.

Sue Capel is undertaking her full-time doctoral research at Northumbria University. She also has professional experience of providing information to patients and the public for the NHS.

Email: linda.banwell@northumbria.ac.uk
\end{abstract}

\begin{abstract}
Despite there being larger numbers of older people in rural populations in the UK, there has been very little research undertaken with this group. The research uses a social ethnographic approach grounded in information and social network theory. The paper describes the progress so far, places the research within a theoretical context, describes the way stage one fieldwork was undertaken and identifies the themes that emerged to inform stage two design. The second stage fieldwork is described using some of the initial findings from the observation, interview and participant diary data collected. The paper concludes that the research will provide a unique insight into the social networking of information amongst active older people in a very rural community in the rural North Pennines and inform the planning of service provider information provision for this population group.
\end{abstract}

\section{Introduction}

Over the last few years the older rural population has grown steadily and many of these older people are determined to remain independent and actively involved in their communities. They see themselves as being healthier and happier if they are part of a strong social network (Manthorpe et. al., 2004, Wenger, 2001, Wenger and Tucker, 2002). Statutory and voluntary providers, such as the NHS and Age Concern, found that vulnerable older people need better access to information to improve their healthy lifestyle (DOH, 2004). However, less vulnerable, more active, older people have been shown to be positive, and to take a self-help view of their health and social problems by sharing information within social networks (Quinn et al, 2003, Chatman, 1991). Research undertaken in rural East Cumbria with Age Concern Eden showed social networks as a common source of help for older people (Kolek, 1993, Wenger \& Tucker, 2002). This doctoral research uses a social ethnographic approach, grounded in information science, to investigate the 'information worlds' of people over sixtyfive in an East Cumbria rural community to "learn about unconventional, socially based information resources" (Lievrouw and Farb, 2003, 529). The ways in which healthy lifestyle information is identified, communicated, and shared within social networks was explored during two stages of fieldwork using several data collection methods, including participant observation, focus groups, in-depth interviews, structured interviews and participant selfcompleted diaries.

\section{Theoretical Context}

Identification with a social group leads to an increase in social capital, 'social sharedness', and the enhancement of information sharing within the group (Ginman, 2003). It is important to describe the 'information worlds' and the information 'sense-making' of individuals within their own social and life activities (Savolainen, 1993, Sonnenwald, 1998). This enables the researcher to "seek a better understanding of the seekers themselves ... as well as the intricate variability of human 
contexts and information-seeking behaviour" (Lievrouw and Farb, 2003, 528). Fisher (as Pettigrew) defined the concept of 'information grounds' as "synergistic environment(s) temporarily created when people come together for a singular purpose but from whose behaviour emerges a social atmosphere that fosters the spontaneous and serendipitous sharing of information" (Pettigrew, 1999, 811, Fisher and Naumer, 2005). The concept of information grounds fits well with the network theory of social capital, rooted in the concepts of social network analysis and the theory of the 'strength of weak ties' (Granovetter, 1973, Johnson, 2004, Haythornthwaite, 1996). However, the association between social ties and routine information flow within and between networks is seldom examined according to Lai and Wong (Lai and Wong, 2002). An aim of this research is to relate the findings of this in-depth, ethnographic study in one location to existing information and social network theories.

\section{Data Collection Stage One}

The first stage of the research took place from January to March 2005. Initially, representatives of information provider organisations, such as the NHS, Social Services and Age Concern, were interviewed, and a focus group held with Age Concern volunteers. This informed the planning of data collection and provided pointers to issues of concern for rurąl older people. Leaders of activity groups in three small rural towns in East Cumbria were accessed through Age Concern Eden and Carlisle Age Concern contacts, and consent was gained for participation in activities. The researcher acted as a participant observer for a short while in three activity groups in two small rural towns over a six-week period. Participant observation was considered to be the most effective way of becoming familiar with activities undertaken by older people and of gaining the confidence of individuals within their social context whilst remaining in the role of researcher (Erlandson, 1993, Silverman, 1985). Focus groups were then held with small groups of active older people in the two small towns and one village location using adapted versions of the Nominal Group Technique (NGT) approach in order to clarify the main healthy lifestyle information use (Morgan, 1988).

The analysis of the data showed that providers believed financial and benefits issues to be of major concern to older people. They saw their role as identifying and supporting the practical and psychological needs of vulnerable older people. The older people themselves were more concerned about healthy lifestyle issues and safety and security in the home. Most of the older people knew one another and would share information in the street, in the village hall, at a club or activity, at the Day Centre at the church and in many other places. Friends and family were considered the most important contacts for information, whether in person or by telephone. The general consensus was that people needed to make an effort to join in with groups in order to benefit their own healthy lifestyle. The themes identified for further exploration in the second stage included healthy lifestyle, safety and security, access to health information and services, social and family networks, information sharing and gender, and how younger old people relate to older old people.

\section{Data Collection Stage Two}

Data collection for the second stage took place between June and December 2005 through participant observation in activity groups, indepth interviews, short social network mapping interviews and participant diaries. It was decided to continue in one remote rural area and increase the ethnographic participatory approach to data collection in order to provide a "direct view of information behaviour" (Cooper, Lewis and Urquhart, 2004, 1-2). The general direction of the fieldwork moved from formality to informality, from structure to flexibility and from wide coverage to depth in one location. Observation took place within several social activities and groups including the Age Concern Coffee morning, an exercise group, a 'Tai Chi in the water' session, and an Arts and Crafts club, consent for researcher attendance being gained through group leaders. One-off activities and events organised by and for older people, such 
as day coach trips and entertainments, were also attended at the invitation of group leaders and individuals.

The sample for interviews were accessed through personal contact and the snowballing effect, and sixteen depth interviews were undertaken, eleven with women and five with men. Participants were a mix of active people who had lived in the area all their lives and those who had chosen to move to the area. Their ages ranged between sixty-five and ninety-four and their mobility level also varied. Participants were asked about what it was like to live in the locality, the advantages and disadvantages of their lifestyle, social and family connections, their healthy lifestyle activities and their information need and activity. In-depth interviews were followed by short, structured interviews to gather information about participants' social network contacts. They were asked to think of five or six people with whom they had social contact on a regular basis and asked a series of questions to assess the strength and importance of that contact. Social network analysis can be used in a qualitative context "to collect richly contextualised research material about the nature of the participants' information relationships" (Olsson, 1998, 5).

Five participants were identified to undertake the writing of daily diaries for two weeks, taking into account a range of backgrounds and their ability and willingness to take part. Each of the five agreed and all opted to write a paper diary. The purpose of the daily journal was to help participants remember who they had talked to and what they had discussed each day over a period of two weeks. Once they had completed the journal they were interviewed again to discuss what they had written. The results from different participants were very varied in terms of activity level and amount of material recorded; understanding of and commitment to the task also varied from a diary containing detailed written material, together with examples of paper information, to just a few lines of written material for each day.

\section{Initial Findings from Stage Two}

A fairly large proportion of the older population in the location take part in activities, including some people who have physical health problems. Although there are church 'worthies' and voluntary organisation workers organising groups, several groups are started or managed by older people themselves. Activities, unless very formal, act as a strong focus for people to exchange information and the coffee morning is a good example, providing one hour of intense information exchange between key members of social networks. It is only possible at this stage to provide a taste of some of the views and issues arising from interview data and to discuss the initial analysis of the social network questionnaire.

Most interviewees felt that the area was a relatively safe place to live because people knew about one another. The lack of suitable transport is a problem for those without a car but people share car transport where they can and use the regular bus service and coach trips to do shopping where possible.

I'm ok at the moment, I've got a car, I can go anywhere but the isolation for people who don't have transport, its not good ... but the good thing is that I think that brings the community together.

(Female 65)

The people interviewed were involved in a great many local activities and there was a general attitude amongst them that it was important to keep active even if your health was not as good as it had been in the past.

I'm in the Indoor Bowls, and Keep Fit, I'm in the Crafts, I work in the Charity Shop once a fortnight unless I'm called upon to do more ... I don't know how I find time to do me housework and me washing and everything.

(Female 70)

Interviewees were clear that most of the information they needed was gathered from other people and supplemented with printed information in the form of leaflets, newsletters and posters. 
Say its whist drives or dominoes or anything like that, if you go to one, everybody that's got something on in the area will bring a notice in and it will be read out ... or if there's dances or anything on in the area somebody will ring up and say ... if I want any information I can soon get to know.

(Female 72)

I find out through leaflets and people talking ... I use the information centre sometimes, I don't use the library, my literature is motorbikes and motoring magazines.

(Male 79)

The initial analysis of the social network questionnaire provides some information as to who the important contacts were for the interviewees and what kinds of information these contacts can provide. When asked about the first regular contact that came to mind, eight of the twelve interviewees thought of family members first and the other four thought of friends. The subsequent five contacts were predominantly friends with some family members. The eight had very regular contact with one or more of their family, either daily or several times a week, and this contact might be in person or on the telephone.

Contacts with friends were mostly at least weekly or several times a week. When they were asked what sort of social contact was provided, they were clear that friendship, support, and information were fairly equally spread. Advice came out with a slightly lower score and comments from some suggested that they did not need advice or were the advisors themselves. When asked what kinds of information were provided by their social contacts they highlighted a wide variety of areas as seen in Table 1 below. A more in-depth analysis may show what kinds of information are provided by contacts who are strong to weak in tie strength and which contacts stand out as key information providers.

\begin{tabular}{|l|l|}
\hline Town events & Help with paperwork \\
\hline News about local issues & Holiday information \\
\hline Family news and business & About people in care homes/hospital \\
\hline Social activities and groups & Pastoral issues and the church \\
\hline Internet information & News from Penrith or Hexham \\
\hline Mutual interests & Outings \\
\hline Local gossip & Politics \\
\hline Health information & Sport \\
\hline Church information & Farming \\
\hline Music activities & Age concern shop and activities \\
\hline Practical and technical & Official information \\
\hline Food & Cultural and books \\
\hline
\end{tabular}

Table 1: Information provided by social contacts

\section{Conclusions}

The observation, interview and participant diary data collected in this research will be analysed fully and the findings related to existing theory and models in order to inform and add to the existing body of knowledge in the fields of information and social gerontology. The research will provide a unique insight into the social networking of information amongst active older people in a very rural community in the north Pennines area of Cumbria and inform the planning of service provider information provision for this population group. 


\section{References}

Chatman, E. (1991) Channels to a larger social world: older women staying in contact with the greater society. Library and Information Science Research 13, 281-300.

Cooper, J., Lewis, R. and Urquhart, C. (2004) Using participant and non-participant observation to explain information behaviour. Information Research 9(4), 1- I8, Available from: http://informationr.net/ir/ 9-4/paperl84.html [I7/0I/2006]

Department of Health (2004) Better information, better choices, better health: putting information at the centre of health. London, DOH.

Erlandson, D.A. et al. (1993) Doing naturalistic inquiry. London: Sage.

Fisher, K and Naumer, C. (2005) Something old, something new: preliminary findings from an exploratory study about people's information habits and information grounds. Information Research 10(2), I-19, Available at: http://informationr.net/ir/ 10-2/paper223.html [12/10/2005]

Ginman, M. (2003) Social capital as a communicative paradigm. Health Informatics Journal, 9(I), 57-64.

Granovetter, M.(1973)The strength of weak ties. American Journal of Sociology,78, $1360-80$.

Haythornthwaite, C. (1996) Social network analysis: an approach and technique for the study of information exchange. Library and Information Science Research, 18, 323-342.

Johnson, C.A. (2004) Choosing people: the role of social capital in information seeking behaviour. Information Research, 10(1), 1-16, Available at: http://informationr.net/ir/l0-I/paper20I.html [09/06/2005]

Kolek, C.R. (1993) Elderly people in Eden: independence and the supportive network. Penrith:Age Concern Eden.

Lai, G. \& Wong, O. (2002) The tie effect on information dissemination: the spread of commercial rumour in Hong Kong. Social Networks, 24, 49-75.

Lievrouw LA, Farb SE. (2003) Information and equity. Annual Review of Information Science and Technology, 37(I I), 499-540.

Manthorpe, J., Malin, N. and Stubbs, H. (2004) Older people's views on rural life: a study of three villages. Journal of Clinical Nursing, I3 (6b), 97- 104.
Morgan, D. (1988) Focus groups as qualitative research. London: Sage.

Olsson, M. (1998) The discourses of contemporary information science research: an alternative approach. Information Research, 4(2), I-6, Available at: http://InformationR.net/ir/4-2/isic/olsson.html $[\mid 7 / 01 / 06]$

Pettigrew, K.E. ( 1999) Waiting for chiropody: contextual results from an ethnographic study of the information behavior among attendees at community clinics. Information Processing and Management, 35(6), 801-817.

Quinn A, Snowling A, Denicolo P. (2003) Older people's perspectives: devising information, advice and advocacy services. York: Joseph Rowntree Foundation.

Savolainen, R.(1993)Sense-making theory: reviewing the interests of a user-centred approach to information seeking and use. Information Processing and Management,29(I), 13-28.

Silverman, D. (1985) Qualitative methodology and sociology. Aldershot: Gower.

Sonnenwald, D.H. (1998) Evolving perspectives of information behavior: Contexts, situations, social networks and information horizons. In: Exploring the contexts of information behaviour: proceedings of the second international conference on research in information needs, seeking and use in different contexts. Sheffield, UK. 13-I5 August. London: Taylor Graham.

Wenger, G. Clare. (200I) Myths and realities of ageing in rural Britain. Ageing and Society, 21, I I7-130.

Wenger, G. Clare and Tucker, I. (2002) Using network variation in practice: identification of support network type. Health and Social Care in the Community, IO(I), 28-35. 